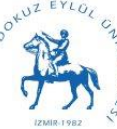

ISSN: 1308-8173

Geliş Tarihi: 04.01.2018
E-ISSN: 1308-8505

Kabul Tarihi: 21.10 .2019
YIL: 2019

Online Yayın: 25.10.2019
Cilt:34 Sayı:3 Sayfa: 311-320

Doi: $10.24988 /$ ije. 2019343723

\title{
Niceliksel Gevşeme Politikalarının Kamu Maliyesi Etkisi Mesut TÜRKAY1
}

\section{Özet}

Çalışmanın amacı, 2008-2009 küresel ekonomik krizi sonrası dönemde yaygın bir biçimde uygulanan niceliksel gevşeme politikalarının kamu maliyesi üzerindeki etkisini ABD örneği üzerinden analiz etmektir. ABD’nin niceliksel gevşeme politikaları borçlanma faiz oranlarını düşürerek bütçedeki faiz harcamalarını azaltmış, ekonomik aktiviteyi canlandırarak vergi gelirlerini artırmış ve Merkez Bankası'nın Hazine'ye olan kar transferlerini artırarak vergi dışı bütçe gelirlerinin yükselmesine neden olmuştur. Tüm bunların sonucunda, bütçe açığı ve kamu borç stoku bu politikaların uygulanmadı̆̆ı duruma göre daha düşük gerçekleşmiştir. Dolayısıyla, gelişmiş ülke merkez bankalarının uyguladığı niceliksel gevşeme politikiları kamu maliyesine olumlu etkiler yaparak borcun sürdürülebilirliğine katkı sağlamıştır.

Anahtar kelimeler: Niceliksel Gevşeme, Kamu Maliyesi, Borcun Sürdürülebilirliği

Jel Kodu: E58, E63, H62, H68

\section{Public Finance Effect of Quantitative Easing Policies}

Abstract

The purpose of the study is to analyze the impact of quantitative easing (QE) policies on public finance through the case study of United States. Quantitative easing policies of United States have reduced interest expenditures by lowering government bond interest rates, have increased tax revenues by supporting economic activity and have enhanced non-tax budget revenue by increasing Central Bank profit transfers to Treasury in United States. As a consequence of these, budget deficit and public debt stock have declined compared with no policy scenario. Hence, quantitative easing policies implemented by advanced country central banks have made positive effects to public finance and contributed to debt sustainability.

Keywords: Quantitative Easing, Public Finance, Debt Sustainability Jel Codes: E58, E63, H62, H68

\section{GíRiş}

2008 yılında ortaya çıkan küresel ekonomik kriz etkileri bakımından İkinci Dünya Savaşı sonrası dönemin en büyük krizi olarak görülmektedir. Söz konusu krizle mücadele etmek amacıyla gerek hükümetler gerekse merkez bankaları kapsamlı politikalar uygulamışlardır. Hükümetler çeşitli vergi indirimleri, altyapı harcamalarının artırılması ve yatırım teşvikleri gibi yollarla ekonomiyi desteklemişlerdir. Merkez bankaları ilk aşamada faiz indirimleri ve likidite destekleri uygulamış, özellikle önde gelen gelişmiş ülke merkez bankaları faiz oranlarının sıfıra yaklaşmasıyla birlikte geleneksel olmayan para politikalarına başvurmuşlardır. Bunların arasında, niceliksel gevşeme politikaları yaygın bir biçimde uygulanmış, gelişmiş ülke merkez bankaları devlet tahvili ve ipoteğe dayalı tahvil başta olmak üzere çeşitli finansal varlıkların satın alınması yoluyla bilançolarını önemli ölçüde büyütmüşlerdir. $\mathrm{Bu}$ şekilde merkez bankaları para yaratmış, parasallaşma süreci bir taraftan faiz oranlarının düşmesine, diğer taraftan da ekonomik aktivitenin canlanmasına neden olmuş ve hem finansal hem reel değişkenleri etkilemiştir.

Küresel ekonomik kriz sonrası dönemde uygulanan niceliksel gevșeme politikalarının ekonomi üzerindeki etkilerine yönelik çok sayıda çalışma bulunmaktadır. Genel olarak bakıldığında, çalışmaların bulguları bu politikaların kamu borçlanma faiz oranlarını düşürdüğünü, ekonomik aktiviteyi desteklediğini, enflasyonu yükselttiğini, varlık

\footnotetext{
${ }^{1}$ Hazine ve Maliye Uzmanı, Dr., Hazine ve Maliye Bakanlığı, Çankaya/ANKARA, email adresi: mesut.turkay@hmb.gov.tr ORCID:0000-0002-3364-385X
} 


\section{TÜRKAY}

fiyatlarını ve gelișmekte olan ülkelere yönelik sermaye akımlarını arttırdığını göstermektedir. Fakat, bu alandaki zengin literatüre rağmen, niceliksel gevşeme politikalarının kamu maliyesi etkisine yönelik kapsamlı ve sayısal bir analiz bulunmamaktadır. Bu çalışmanın temel amacl, dünyanın en büyük ekonomisi olan ABD örneği üzerinden hareketle literatürdeki bu boşluğu doldurarak, söz konusu literatüre katkı sağlamaktır.

Çalışmanın ikinci bölümünde niceliksel gevşeme politikalarının ekonomiyi etkileme kanalları analiz edilecektir. Üçüncü bölümde, bu politikaların çeşitli ekonomik göstergeler üzerindeki etkisine ilişkin literatür taraması yapılacaktır. Dördüncü bölümde, literatürde bulunan sonuçlardan yola çlkılarak ve birtakım basitleștiri varsayımlar kullanılarak ABD'de uygulanan niceliksel gevşeme politikalarının ülkenin kamu maliyesi üzerindeki etkisine yönelik bir hesaplama yapılacaktır. Beşinci ve son bölümde ise çalışmanın sonuçları ve literatüre katkısı tartışılacaktır.

\section{NİCELİKSEL GEVŞEMENİN EKONOMIYE ETKİ KANALLARI}

Para politikasının aktarım kanalları literatürde yaygın ve kapsamlı bir biçimde ele alınmıştır. Geleneksel para politikasının aktarım mekanizması 1990'lı yıllarda sıklıkla analiz edilmişken, niceliksel gevşeme politikalarını da kapsayan geleneksel olmayan para politikalarının etki kanalları özellikle 2008-09 küresel ekonomik krizi sonrası dönemde bu politikaların yaygın bir şekilde uygulanmasıyla birlikte incelenmeye başlanmıştır.

Niceliksel gevşeme politikalarının aktarım kanallarının başında ticaret kanalı gelmektedir. Standart Mundell-Fleming modeline göre genişletici para politikası yurtiçi çıktı düzeyini yükseltmekte ve ithalat talebini yükselterek diğer ülkelerin ekonomik aktivitesini olumlu yönde etkilemektedir. Baumaister ve Benati (2013), Meinush ve Tillman (2016) ve Weale ve Wieladek (2016) niceliksel gevşemenin ticaret kanalına ilişkin ampirik bulgular sunan çalışmalar arasında yer almaktadır. Bu çalışmaların sonuçlarına gore, uygulanan niceliksel gevşeme politikaları ülkenin ekonomik aktivitesinin artmasına neden olmuştur. Artan büyüme ithalat talebini yükselterek diğer ülkelerin milli gelirini de olumlu yönde etkilemektedir.

Mundell-Fleming modeline göre parasal genişleme politikası yerel para biriminin değer kaybetmesine yol açmaktadır (Glick ve Leduc, 2013; Neely, 2015). Döviz kuru kanalına göre, para biriminin değer kaybetmesi ülkenin ihracatını artırmakta, ithalatını ise olumsuz yönde etkilemektedir. Ayrıca, bu kanala göre net dıș talep artmakta, cari işlemler dengesi de pozitif yönde etkilenmektedir.

Güven kanalına göre, niceliksel gevşeme politikasının açıklanması ve uygulanmasıyla merkez bankaları ekonomiyi desteklemeye yönelik gerekeni yapacağının mesajını piyasalara vererek gerek üretici gerekse tüketici güvenini artırmaktadır. Uygulanan bu politikalar sonucunda tüketim ve yatırımlar olumlu yönde etkilenirken, belirsizlik ve risk primi azalmakta, varlık fiyatları ise artmaktadır (Fratzscher vd., 2013)

Likidite kanalına göre merkez bankalarının varlık alımları likiditenin sıkışık olduğu sıkıntılı zamanlarda piyasaların işleyişini iyileștirmekte ve likiditeyi artırmaktadır. Böylece özellikle kriz zamanlarında piyasalar rahatlamakta, panik ortadan kalkmakta, risk primi düşmektedir (Gagnon vd., 2011). Ayrıca bankaların rezervleri artmakta, finansman maliyeti azalmakta ve bankaların kredileri artırmasına olanak sağlanmış olmaktadır.

Portföy dengesi kanalına göre, yatırım yapılabilir varlık arzındaki değişim fiyat ve getiriyi etkilemektedir. Merkez bankalarının varlık alımları yatırım yapılabilir varlıkların arzını azaltarak fiyatlarını artırmaktadır. Bunun sonucunda getiri arayışındaki yatırımcılar portföylerini yeniden oluşturmaktadır. Merkez bankalarının ikincil piyasadan kamu tahvili alması, talebi arttırarak tahvil fiyatını yükseltmekte, faizini ise düşürmektedir. Bu varlık sınıfındaki getirinin azalmasıyla yatırımcilar hisse senetleri ve şirket tahvilleri gibi alternatif yatırım 
araçlarına olan talebi arttırarak onların fiyatını etkilemektedir. Düşen faiz oranı ve yükselen varlık fiyatları finansal koşulları iyileștirmekte, azalan finansman maliyeti ve servet etkisiyle yatırım ve tüketimi artırmaktadır. Bauer ve Neely (2014), Neely (2015) ve Tillmann (2016) niceliksel gevşeme politikalarının portföy dengesi kanalıyla faiz oranını düşürüp ekonomik aktiviteyi canlandırdığını gösteren ampirik çalışmalar arasındadır.

Sinyal (beklentiler) kanalına göre, merkez bankaları varlık alımı yapacağını duyurarak ve fiilen alım yaparak ekonominin mevcut durumuna ve para politikasının geleceğine yönelik sinyal vermektedir. Merkez bankaları bu şekilde ekonominin zayıf olduğuna ve para politikasının ilerleyen dönemde genişlemeci olacağına yönelik işaret vermekte, faiz oranlarının uzun süre düşük kalacağını ima etmekte ve bu yolla beklentileri etkileyerek faizlerin düșmesini sağlamaktadır (Bauer ve Neely, 2014). Niceliksel gevșeme politikaları bu kanalla belirsizliği azalmakta, oynaklık ve risk primini düşürmekte, kredi koşullarını iyileştirmekte, güveni ve varlık fiyatlarını artırarak ekonomik aktiviteyi pozitif yönde etkilemektedir. Oda ve Ueda (2007), Thornton (2012) ve Bauer and Rudebusch (2014) niceliksel gevşeme politikalarının sinyal kanalının ekonomiye olumlu etkilerini ampirik olarak inceleyen çalışmalar arasında yer almaktadır.

Çalışmamızın odak noktası olan kamu maliyesi kanalına göre, merkez bankalarının niceliksel gevşeme politikaları kamu borçlanma enstrümanlarına olan talebi artırarak faiz oranını düşürmekte, bütçe harcamalarının önemli kalemlerinden biri olan faiz harcamalarından tasarruf edilmesini sağlamaktadır (Kozicki vd., 2011). Niceliksel gevşeme politikaları bütçenin gelir tarafını da olumlu yönde etkilemektedir. Uygulanan politikalar çıktı düzeyini yükselterek daha fazla vergi toplanabilmesine imkan tanımakta ve vergi gelirlerini artırmaktadır. Ayrıca, merkez bankalarının varlık alımları sonucunda bilançolarında tuttuğu tahvillerden elde ettiği faiz geliri merkez bankalarının karını artırmakta, karın büyük bir çoğunluğu hazineye transfer edilerek vergi dışı gelirleri artırmaktadır. Örneğin, ABD Merkez Bankası 2016 yılı karı olarak 92 milyar doları ABD Hazine'sine transfer etmiştir. Dolayısıyla, niceliksel gevșeme politikaları harcamaları azaltıp gelirleri artırarak bütçe dengesini iyileştirmekte, borç stokunu politikaların uygulanmadığı duruma göre düşürmektedir.

\section{LITTERATÜR TARAMASI}

Merkez bankalarının uyguladığı niceliksel gevșeme politikalarının çeşitli ekonomik değişkenler üzerindeki etkisine ilişkin çalışmalar özellikle 2008-09 küresel ekonomik krizi sonrası dönemde bu politikaların yaygın bir biçimde uygulanmaya başlamasıyla hızlı bir artış göstermiştir. Söz konusu literatürü, niceliksel gevşemenin finansal değişkenlere ve reel ekonomik değişkenlere etkisini analiz eden çalışmalar olarak iki gruba ayırmak mümkündür.

Birinci gruptaki çalışmalar uygulanan bu politikaların faiz oranı, döviz kuru ve borsalar gibi finansal değişkenler üzerindeki etkisini ampirik olarak incelemektedir. Bu çalışmaların büyük çoğunluğu faiz oranı üzerindeki etkiyi analiz etmektedir. Örneğin Gagnon vd. (2011) olay inceleme yaklaşımıyla ABD'de uygulanan birinci niceliksel gevşeme programının 10 yıllık devlet tahvili faizi üzerindeki etkisini $91 \mathrm{baz}$ puan olarak bulmuştur. Krishnamurthy ve Jorgenson (2011) de aynı yaklaşımla ABD'deki birinci ve ikinci niceliksel gevşeme programının devlet tahvili faizine etkisini sırasiyla 107 ve 30 baz puan olarak hesaplamıştır. Joyce vd. (2011) aynı yöntemle İngiltere'de uygulanan niceliksel gevşemenin devlet tahvili faizine etkisinin yaklaşı $100 \mathrm{baz}$ puan olduğunu tahmin etmiştir. Hancock ve Passmore (2011) ABD'deki ipoteğe dayalı menkul değer alımlarının ipotek teminatlı faiz oranını düşürmede oldukça başarılı olduğunu saptamıştır. Chen vd. (2012b) gelişmiş ülkelerin niceliksel gevşeme uygulamalarının gelişmekte olan ülke finansal değişkenleri üzerindeki etkisini analiz etmiştir. Çalışmanın 


\section{TÜRKAY}

sonuçları bu politikaların gelișmekte olan ülkelerde borsaları yükselttiğini, devlet ve şirket tahvili faizlerini düşürdüğünü, para birimlerinin değer kazanmasına neden olduğunu, risk primini düşürüp finansal koşulları iyileștirdiğini göstermektedir. Li ve Wei (2013) ABD için vade yapısı modelleri kullanarak niceliksel gevşemenin devlet tahvili faizine etkisini incelemiş ve etkiyi birinci ve ikinci niceliksel gevşeme programları için sırasıyla 60 ve 19 baz puan olarak bulmuştur. Glick ve Leduc (2013) ABD'de uygulanan niceliksel gevşeme programlarının doların değer kaybetmesine neden olduğunu saptamıştır. Szczerbowicz (2015) Avrupa Merkez Bankası'nın varlık alımlarının bankaların ve hükümetlerin borçlanma maliyetlerini düşürdügünü olay inceleme yaklaşımıyla tespit etmiştir. Neely (2015) ABD'deki geleneksel olmayan para politikalarına ilişkin açıklamaların ABD, Kanada, Japonya, Avustralya, Almanya ve İngiltere'nin 10 yıllık devlet tahvili faizine etkisini analiz etmiștir. Çalışmanın bulgularına göre, politikaların faiz oranı üzerindeki etkisi Japonya'daki 18 baz puanla Avustralya'daki 65 baz puan arasında değișmektedir. Georgiadis ve Gräb (2016) Avrupa Merkez Bankası'nın genişletilmiş varlı alım programı açıklamasının etkilerini araştırmıştır. Sonuçlara göre, açıklama küresel borsaları yükseltmiş, avro para biriminin değer kaybetmesine neden olmuş ve tahvil faizleri üzerinde sınırlı bir etki yaratmıştır. Gelişmekte olan ülkelerin borsa ve döviz kurları açıklamaya gelişmiş ülkelere göre daha fazla tepki vermiştir. Lim ve Mohapatra (2016) ise niceliksel gevşeme politikalarının gelişmekte olan ülkelere yönelik sermaye akımlarına etkisini incelemiştir. Çalışmanın sonuçlarına göre, 2009 ve 2013 yılları arasındaki sermaye akımlarınının yüzde 13'ü niceliksel gevşeme politikaları kaynaklıdır. Ayrıca, portföy akımları doğrudan yabancl sermaye yatırımlarına göre niceliksel gevşeme politikalarına daha duyarlı bulunmuştur.

Literatürün ikinci grubundaki çalışmalar gelişmiş ülke merkez bankaları tarafından uygulanan niceliksel gevşeme programlarının reel ekonomik değişkenler üzerindeki etkisini analiz etmektedir. $\mathrm{Bu}$ gruptaki çalışmalar politikaların özellikle büyüme, sanayi üretimi ve istihdam üzerindeki etkisine odaklanmıştır. $\mathrm{Bu}$ çalışmalardan Lenza vd. (2010) Bayezyen Vektör Otoregresif modeliyle İngiltere'deki geleneksel olmayan para politikasının etkisini incelemiştir. Model sonuçlarına göre bu politikalar işsizliği 0,6 yüzde puan düşürüken sanayi üretimini 2 yüzde puan artırmaktadır. Kapetanios vd. (2012) İngiltere'de uygulanan niceliksel gevşeme programının ekonomik aktiviteye etkisini çeşitli VAR modelleri yoluyla analiz etmiştir. Model sonuçlarına göre niceliksel gevşeme çıktıyı yüzde 1,5 oranında yükseltmiştir. Chung vd. (2012) farklı modeler kullanarak ABD Merkez Bankası Fed'in uyguladığı ilk 2 niceliksel gevşeme programının hiçbir politika uygulanmayan duruma göre çıktıyı 3 yüzde puan yükselttiğini bulmuştur. Ayrıca, bu programlarla ABD'de 3 milyon kişilik istihdam sağlanmış ve ișsizlik oranı 1,5 yüzde puan düșmüştür. Gertler ve Karadi (2013) hesaplanabilir genel denge modeli kullanarak ABD'de uygulanan ikinci niceliksel gevşeme programının çıktıyı 1 yüzde puan artırdığını tahmin etmektedir. Baumeister ve Benati (2013) zamana göre değișen katsayılı vektör otoregresif modeli kullanarak ABD'de uygulanan birinci niceliksel gevşeme programının çıktıyı 0,9 yüzde puan yükselttiğini bulmuştur. Weale ve Wieladek (2016) Bayesyen VAR modeliyle ABD'de milli gelirin yüzde 1'ine tekabul eden varlık alımlarının çıktıyı 0,58 yüzde puan yükselttiğini bulmuștur. Paseran ve Smith (2016)'in analizi İngiltere'deki varlık alımlarının kısa ve uzun vadeli tahviller arasındaki faiz farkını 100 baz puan azalttığını ve büyümeyi 1 yüzde puan artırdığını göstermektedir.

Niceliksel gevşeme politikalarının reel ve finansal ekonomik değişkenler üzerindeki etkisine ilişkin literatür oldukça zengin olmasına rağmen bu politikaların kamu maliyesi etkisine yönelik ampirik yada sayısal bir analiz bulunmamaktadır. Bu çalışma söz 
konusu eksikliği gidermeyi ve literatüre katkı sağlamayı amaçlamaktadır.

\section{VERİ, YÖNTEM VE HESAPLAMALAR}

Çalışmanın bu bölümünde mevcut veriler, literatürdeki bulgular ve birtakım basitleştirici varsayımlardan hareketle ABD'de uygulanan niceliksel gevşeme politikalarının ülkenin kamu maliyesine etkisine ilișkin sayısal bir hesaplama yapilacaktır. $\mathrm{Bu}$ hesaplamanın amacı uygulanan niceliksel gevșeme politikalarının kamu maliyesi etkisine ilişkin kesin bir sonuç bulmaktan ziyade ortalama tahmini etkiyi ortaya koymak ve ileride benzer konularda ve başka ülkelerle ilgili yapılabilecek çalışmalara yol açmaktır.

Çalışmanın ikinci bölümünde üzerinde durulduğu üzere, niceliksel gevșeme politikaları kamu maliyesini temelde 3 farklı kanaldan etkilemektedir. Düșen faiz oranı bütçede faiz harcamalarını azaltmakta, politikaların sonucunda canlanan ekonomik aktivite vergi gelirlerini artırmakta ve Merkez Bankası'nın Hazine'ye kar transferleri vergi dıșı bütçe gelirlerini yükseltmektedir. Bu bölümde söz konusu 3 ayrı etki ABD için hesaplanarak niceliksel gevșemenin ABD'nin kamu maliyesine olan etkisinin boyutu tahmini olarak ortaya konulacaktır.

ABD'deki niceliksel gevșemenin faiz harcamalarına olan etkisi hesaplanırken literatürdeki mevcut çalışmalardan faydalanılacaktır. Tablo 1'de ABD'de uygulanan 3 niceliksel gevşeme programının devlet tahvili faizi üzerindeki etkisine ilişkin literatür sunulmaktadır. Yapılan çalışmalara göre birinci niceliksel gevşeme programının devlet tahvili faizini düşürücü etkisi ortalama 73 baz puan, ikinci ve üçüncü niceliksel gevşeme programlarının ortalama etkileri ise sırasıyla 21 ve 11 baz puandır.

Söz konusu niceliksel gevşeme programlarının uygulanmadiğı durumda borçlanma maliyetlerinin literatürdeki çalışmalarda belirtildiği üzere Tablo 1'deki ortalama etki kadar daha yüksek olacağı varsayılmaktadır.
Tablo 1: Niceliksel Gevșemenin Devlet Tahvili Faizine Etkisi (Baz Puan).

\begin{tabular}{|l|l|l|l|}
\hline \multicolumn{1}{|c|}{ YAZAR QE1 } & QE2 & QE3 \\
\hline Doh (2010) & -39 & & \\
\hline Gagnon vd. (2011) & -91 & & \\
\hline $\begin{array}{l}\text { Krishnamurthy ve } \\
\text { Jorgenson (2011) }\end{array}$ & -107 & -30 & \\
\hline $\begin{array}{l}\text { Meaning ve Zhu } \\
\text { (2011) }\end{array}$ & -80 & -21 & \\
\hline D'Amico vd. (2012) & -35 & -45 & \\
\hline Li ve Wei (2013) & -60 & -19 & \\
\hline $\begin{array}{l}\text { Glick ve Leduc } \\
\text { (2012) }\end{array}$ & -100 & 1 & \\
\hline Fratzscher vd. (2013) & -16 & -2 & \\
\hline Neely (2015) & -94 & & \\
\hline Moore vd. (2013) & -95 & -34 & \\
\hline $\begin{array}{l}\text { Bauer ve Neely } \\
\text { (2014) }\end{array}$ & -123 & -23 & -14 \\
\hline $\begin{array}{l}\text { D'Amico ve King } \\
\text { (2013) }\end{array}$ & -30 & & \\
\hline Swanson (2011) & & -15 & \\
\hline $\begin{array}{l}\text { Swanson ve Williams } \\
\text { (2014) }\end{array}$ & & & -8 \\
\hline Ortalama Etki & $\mathbf{- 7 3}$ & $\mathbf{- 2 1}$ & $\mathbf{- 1 1}$ \\
\hline
\end{tabular}

Tablo 2'de ise ABD'de gerçekleșen borçlanma maliyeti ve faiz ödemeleri, programların uygulanmadığı durumda ortaya çıkacak borçlanma maliyeti ve bu durumdaki faiz ödemesi miktarı gösterilmektedir. Böylelikle politikaların uygulanmadığı durumda faiz ödemesindeki artış ve bunun milli gelire oranı hesaplanmaktadır. Niceliksel gevşemenin uygulanmadığı durumda ortaya çıkacak borçlanma maliyeti, gerçekleşen borçlanma maliyetine Tablo 1'deki ortalama faiz etkisinin niceliksel gevşeme programlarının uygulandığı yıldan sonrasına eklenmesiyle bulunmaktadır. Örneğin, 2016 yllında gerçekleşen borçlanma maliyeti yüzde 2,29 iken niceliksel gevşeme olmasaydı söz konusu borçlanma maliyetinin yüzde $3,34 \quad(2,29+0,73+0,21+0,11) \quad$ olacağ varsayılmaktadır. Niceliksel gevşemenin olmadığı durumda ortaya çıkacak faiz ödemesi ise, bulunan borçlanma maliyeti ile borç stokunun çarpılmasıyla hesaplanmaktadır. Yapılan hesaplamaya göre niceliksel gevşemenin yapılmadığı durumda faiz 


\section{TÜRKAY}

harcamalarında önemli bir artış gerçekleşmektedir. $\mathrm{Bu}$ artış Tablo 2'de son sütundaki rakamların toplanmasıyla 20092016 döneminde milli gelirin toplam yüzde 8,24'ü olarak hesaplanmıştır. Yapılan

hesaplamaya göre, ABD'de niceliksel gevșeme ile birlikte faiz oranlarının ve bütçedeki faiz harcamalarının düşmesiyle ilgili 8 yıllık dönemde milli gelirin toplam yüzde 8,24'ü kadar tasarruf sağlandığı tahmin edilmektedir.

Tablo 2: Niceliksel Gevşemenin Faiz Harcamalarına Etkisi (Baz Puan).

\begin{tabular}{|c|c|l|l|l|l|l|}
\hline Yıl & $\begin{array}{l}\text { Borçlanma } \\
\text { Maliyeti } \\
\text { (Yüzde) }\end{array}$ & $\begin{array}{l}\text { Niceliksel } \\
\text { Gevșeme } \\
\text { Olmasaydı } \\
\text { Maliyet } \\
\text { (Yüzde) }\end{array}$ & $\begin{array}{l}\text { Mevcut } \\
\text { Faiz } \\
\text { Ödemesi } \\
\text { (Milyar } \\
\text { Dolar) }\end{array}$ & $\begin{array}{l}\text { Niceliksel } \\
\text { Gevşeme } \\
\text { Olmasaydı } \\
\text { Faiz } \\
\text { Ödemesi }\end{array}$ & $\begin{array}{l}\text { Faiz } \\
\text { Ödemesindeki } \\
\text { Artış }\end{array}$ & $\begin{array}{l}\text { Faiz } \\
\text { Ödemesindeki } \\
\text { Artışın Milli } \\
\text { Gelire Oranı }\end{array}$ \\
\hline 2009 & 3,49 & 4,22 & 383,1 & 502,9 & 119,9 & 0,83 \\
\hline 2010 & 3,25 & 3,98 & 414,0 & 539,8 & 125,8 & 0,84 \\
\hline 2011 & 3,21 & 4,15 & 454,4 & 613,1 & 158,7 & 1,02 \\
\hline 2012 & 2,33 & 3,27 & 359,8 & 525,7 & 165,9 & 1,03 \\
\hline 2013 & 2,53 & 3,58 & 415,7 & 600,0 & 184,3 & 1,10 \\
\hline 2014 & 2,49 & 3,54 & 430,8 & 631,5 & 200,7 & 1,15 \\
\hline 2015 & 2,24 & 3,29 & 402,4 & 596,7 & 194,2 & 1,07 \\
\hline 2016 & 2,29 & 3,34 & 432,6 & 654,5 & 221,8 & 1,19 \\
\hline
\end{tabular}

Kaynak: ABD Hazinesi, ABD Ekonomik Analiz Bürosu, Yazar Hesaplamaları

ABD'deki niceliksel gevşemenin vergi gelirleri üzerindeki yaklaşık etkisi hesaplanırken faiz etkisine benzer şekilde literatürde bu politikaların çıktı üzerindeki etkisine yönelik çalışmalardan faydalanmak mümkündür. Bununla birlikte, faiz etkisine ilişkin literatürün aksine, çıktı düzeyi üzerindeki etkiyi gösteren çalışma sayısı daha azken, sonuçlar daha geniş bir aralıkta dağılım göstermektedir. Tablo 3'de gösterilen literatürdeki bulgulardan hareketle ABD'deki niceliksel gevşeme politikalarının çıktıyı ortalama 1,5 yüzde puan civarında artırdığını varsaymak mümkündür.

Literatürdeki çalışmalar ABD'deki birinci ve ikinci niceliksel gevşeme programlarının üçüncüye göre reel anlamda daha etkili olduğunu göstermektedir. $\mathrm{Bu}$ nedenle, 1,5 yüzde puanlık kümülatif etki birinci ve ikinci programın uygulandığı 2009, 2010 ve 2011 yıllarında 0,5 yüzde puan olarak dağıtılmıştır. Söz konusu çıktı artışının vergi gelirleri üzerindeki etkisini hesaplamak için vergi gelirinin milli gelire olan esnekliğine ihtiyaç duyulmaktadır. İlgili literature bakıldığında, esnekliğin ABD için 1 civarında olduğu görülmektedir (Dye, 2004). Buradan hareketle, niceliksel gevşemenin neden olduğu çıtı artışının vergi gelirleri üzerindeki etkisi hesaplanabilmektedir.

Tablo 3: Niceliksel Gevşemenin Çıktı Üzerine Etkisi (Yüzde).

\begin{tabular}{|l|c|c|c|}
\hline \multicolumn{1}{|c|}{ YAZAR } & QE1 & QE2 & QE3 \\
\hline Chung vd. (2012) & \multicolumn{2}{|c|}{3} & \\
\hline Chen vd. (2012a) & & 0,13 & \\
\hline $\begin{array}{l}\text { Baumeister ve Benati } \\
(2013)\end{array}$ & 0,9 & & \\
\hline $\begin{array}{l}\text { Gertler ve Karadi } \\
(2013)\end{array}$ & & 1 & \\
\hline $\begin{array}{l}\text { Dahlhaus vd. (2014) } \\
\text { Weale ve Wieladek } \\
\text { (2016) }\end{array}$ & 1,4 & 2,3 & \\
\hline $\begin{array}{l}\text { Meinusch ve } \\
\text { Tillmann (2016) }\end{array}$ & \multicolumn{3}{|c|}{0,15} \\
\hline
\end{tabular}

Așağıdaki Tablo 4'de, ABD'de 2009-2016 döneminde gerçekleşen harcama, gelir ve bütçe açığı ile birlikte niceliksel gevşeme programları 
uygulanmasaydı gerçekleșecek olan tahmini gelir ve bütçe açığı gösterilmektedir. Örneğin, niceliksel gevşeme politikalarının uygulanmaması durumunda ABD'deki vergi gelirinin 2016 yllında 3.268 milyar dolar yerine 3.219 milyar dolar olacağı hesaplanmıștır.
Tablonun son sütununda ABD'de niceliksel gevșeme politikalarının uygulanmadığı durumunda ortaya çıkan vergi kaybının milli gelire oranı verilmektedir. Söz konusu politikaların uygulanmadığı durumda ABD'deki vergi gelirinin 2009-2016 döneminde milli gelirin toplam yüzde 1,71'i kadar daha düşük olacağı hesaplanmıştır.

Tablo 4: Niceliksel Gevșemenin Vergi Gelirlerine Etkisi (Milyar Dolar).

\begin{tabular}{|c|c|c|c|c|c|c|c|c|}
\hline & Harcama & Gelir & Açık & Açı/GSYIH & Gelir* & Açık & Açık/GSYIH* & Fark \\
\hline 2009 & 3.518 & 2.105 & -1.413 & $-9,80$ & 2.094 & 1.423 & $-9,87$ & $-0,07$ \\
\hline 2010 & 3.457 & 2.163 & -1.294 & $-8,65$ & 2.141 & 1.316 & $-8,79$ & $-0,14$ \\
\hline 2011 & 3.603 & 2.303 & -1.300 & $-8,37$ & 2.269 & 1.334 & $-8,60$ & $-0,22$ \\
\hline 2012 & 3.537 & 2.450 & -1.087 & $-6,73$ & 2.413 & 1.124 & $-6,96$ & $-0,23$ \\
\hline 2013 & 3.455 & 2.775 & -680 & $-4,07$ & 2.733 & 721 & $-4,32$ & $-0,25$ \\
\hline 2014 & 3.506 & 3.021 & -485 & $-2,78$ & 2.976 & 530 & $-3,04$ & $-0,26$ \\
\hline 2015 & 3.688 & 3.250 & -438 & $-2,42$ & 3.201 & 487 & $-2,69$ & $-0,27$ \\
\hline 2016 & 3.853 & 3.268 & -585 & $-3,14$ & 3.219 & 634 & $-3,40$ & $-0,26$ \\
\hline
\end{tabular}

Kaynak: ABD Hazinesi, ABD Ekonomik Analiz Bürosu, Yazar Hesaplamaları

Niceliksel gevșeme politikalarının kamu maliyesine etkisinin üçüncü kanalı Merkez Bankası'nın Hazine'ye kar transferi yoluyla vergi dışı gelirleri artırmasıdır. ABD'de uygulanan niceliksel gevşeme programları ile birlikte ABD Merkez Bankası'nın bilançosu 2007 yllı sonundaki yaklaşık 900 milyar dolardan 4,5 trilyon dolar seviyesine yükselmiştir. Bu programlarla birlikte satın alınan tahviller Merkez Bankası'na faiz getirisi sunmuş ve karı artırmıştır. Merkez Bankası'nın karının büyük bir kısmını Hazine'ye transfer etmesi nedeniyle vergi dışı gelirlerde artış gözlenmiştir. Așağıdaki Tablo 5'de yıllara göre ABD Merkez Bankası'nın Hazine'ye yaptığı kar transferleri ve bunun milli gelire oranı gösterilmektedir. Yapılan hesaplamaya göre ABD Merkez Bankası 2009-2016 yılları arasında Hazine'ye milli gelirin toplam yüzde 3,96'sı kadar kar transferi yapmış ve vergi dıșı gelirler bu oranda artmıştır.

ABD Merkez Bankası'nın uyguladığı niceliksel gevşeme politikaları yukarıda açılanan 3 kanaldan bütçe gelirlerini 2009-2016 döneminde milli gelirin 5,67'si kadar artırırken, bütçe harcamaları aynı dönemde milli gelirin yüzde 8,24'ü kadar azalmıştır. Bunların sonucunda bu dönemde bütçe açığı milli gelirin toplam yüzde 13,91'i kadar azalmıştır. Grafik 1, gerçekleşen bütçe açığının milli gelire oranını ve niceliksel gevșeme politikası uygulanmadığı durumda gerçekleşmesi tahmin edilen oranı göstermektedir. Yapılan analize göre, ABD'de uygulanan niceliksel gevşeme politikası bütçe açığığını azaltmış, borcun sürdürülebilirliğine önemli bir katkı sağlamıştır.

Tablo 5: ABD'de Merkez Bankası'nın Hazine'ye Kar Transferleri (Milyar Dolar).

\begin{tabular}{|c|c|c|}
\hline Y11 & Kar Transferi & Milli Gelire Oran \\
\hline 2009 & 47,4 & 0,33 \\
\hline 2010 & 79,3 & 0,53 \\
\hline 2011 & 75,4 & 0,49 \\
\hline 2012 & 88,4 & 0,55 \\
\hline 2013 & 79,6 & 0,48 \\
\hline 2014 & 96,9 & 0,56 \\
\hline 2015 & 97,7 & 0,54 \\
\hline 2016 & 92,0 & 0,49 \\
\hline
\end{tabular}




\section{TÜRKAY}

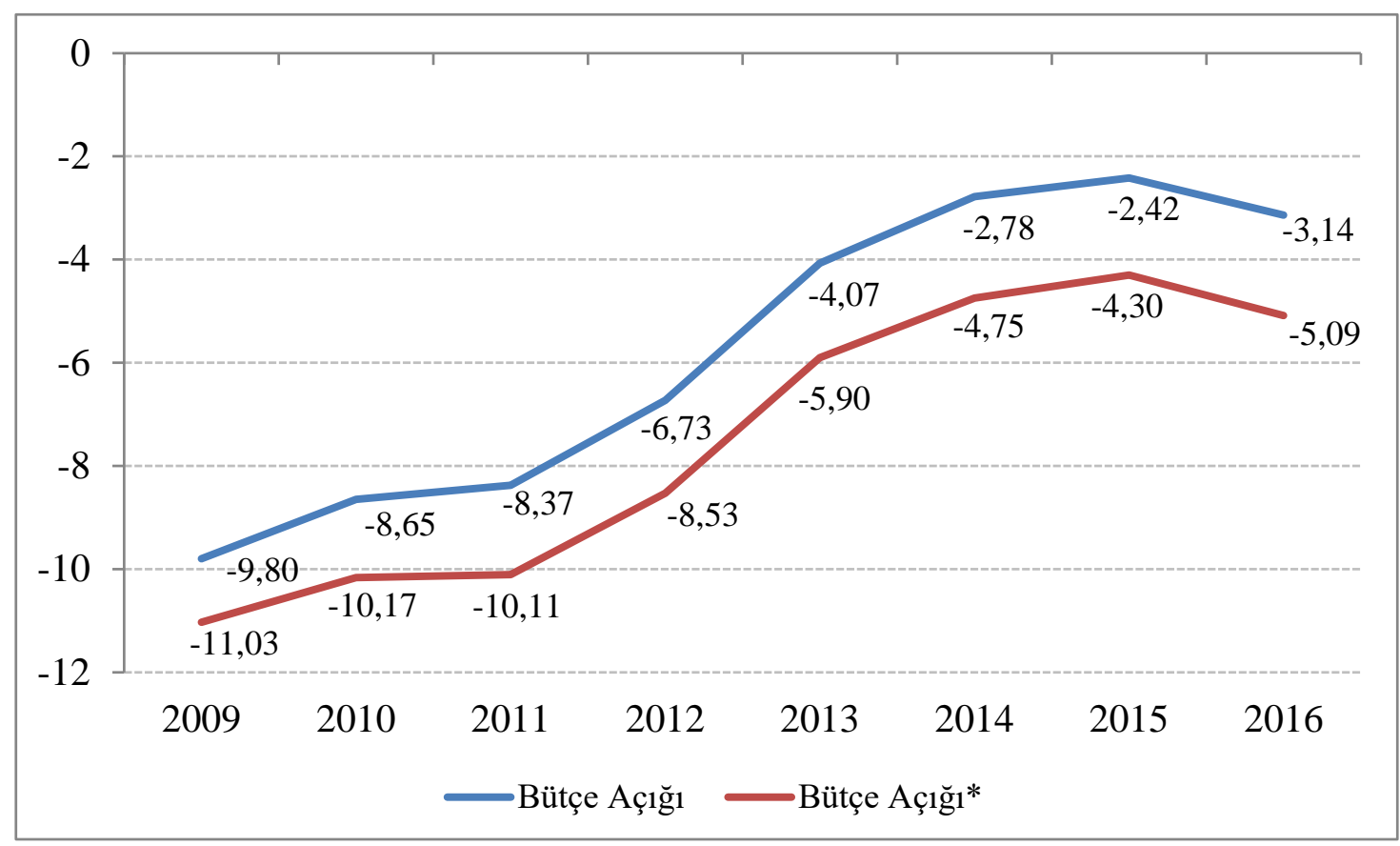

Şekil 1: Bütçe Açığının Milli Gelire Oranı (Yüzde)

Kaynak: ABD Hazinesi, Yazar Hesaplamaları

Not: Bütçe Açığı* niceliksel gevşeme politikası uygulanmadığı durumda gerçekleşeceği tahmin edilen bütçe açığını göstermekteedir.

\section{SONUÇ}

Bu çalışmada ABD Merkez Bankası tarafından küresel kriz sonrası dönemde uygulanan niceliksel gevşeme politikalarının kamu maliyesi üzerindeki etkisi sayısal olarak analiz edilmiştir. Niceliksel gevşeme kamu maliyesini temel olarak 3 farklı kanaldan etkilemektedir. Niceliksel gevşeme politikaları devlet tahvili faizini düşürerek bütçedeki faiz harcamalarını azaltmakta, uygulanan politikaların sonucunda ekonominin canlanmasıyla vergi gelirlerini artırmakta ve Merkez Bankası'nın Hazine'ye olan kar transferlerinin yükselmesiyle bütçede vergi dişı gelirlerin artmasına neden olmaktadır. Tüm bunların sonucunda bütçe açığı politikaların uygulanmadığı duruma göre daha düşük gerçekleşmekte, borç stoku azalmakta ve borcun sürdürülebilirliği iyileşmektedir.

Yapılan hesaplamaya göre, ABD'deki niceliksel gevşeme programları sonucunda bütçe gelirlerinin milli gelire oranının 2009-2016 döneminde toplam 5,67 yüzde puan arttığı, haracamaların 8,24 yüzde puan azaldığı ve bütçe açığının bu dönemde milli gelirin toplam yüzde 13,91'i kadar düştüğü tahmin edilmektedir. Söz konusu hesaplamalar mevcut veriler, literatürdeki çalışmalar, basitleștirici varsayımlar ve diğer herşeyin sabit olduğu (ceteris paribus) varsayımıyla yapılmıștır. Dolayısıyla, çalışmanın amacı ABD'deki niceliksel gevşemenin kamu maliyesi etkisini kesin olarak saptamak değil, bu konuda tahmini bir hesaplama yaparak yöntemsel bir çerçeve geliştirmek ve sonraki çalışmalara yol gösterici olmaktır. Benzer bir yöntemsel çerçeveyle, uygulanan niceliksel gevșeme politikalarının Türkiye gibi ülkelerin kamu maliyesine olan etkisini de analiz etmek mümkündür.

Kriz sonrası dönemde yoğun bir biçimde uygulanan niceliksel gevşeme politikalarının çeşitli ekonomik değişkenler üzerindeki etkisine ilişkin geniş bir literatür bulunmasına rağmen söz konusu politikaların kamu maliyesi üzerindeki etkisine yönelik ampirik yada sayısal bir çalışma bulunmamaktadır. $\mathrm{Bu}$ çalışma, kullanılan yöntem ve yapılan analizle özgün bir nitelik taşımakta ve ilgili literature katkıda bulunmaktadır. Çalışma ayrıca, para ve maliye politikaları arasındaki etkileşimi vermesi açısından önem teşkil etmektedir. 


\section{REFERANSLAR}

Bauer, M. D., ve Neely, C. J. (2014). International Channels of the Fed's Unconventional Monetary Policy, Journal of International Money and Finance, 44, 24-46.

Bauer, M. D., ve Rudebusch, G. D. (2014). The Signaling Channel for Federal Reserve Bond Purchases, International Journal of Central Banking, 10(3), 233-289.

Baumeister, C., ve Benati, L. (2013). Unconventional Monetary Policy and the Great Recession: Estimating the Macroeconomic Effects of a Spread Compression at the Zero Lower Bound, International Journal of Central Banking, 9(2), 165-212.

Chen, H., Curdia, V., ve Ferrero, A. (2012a). The Macroeconomic Effects of Large-scale Asset Purchase Programmes, The Economic Journal, 122(564), F289-F315.

Chen, Q., Filardo, A. J., He, D., ve Zhu, F. (2012b). International Spillovers of Central Bank Balance Sheet Policies, BIS Papers, No.66, 230-74.

Chung, H., Laforte, J. P., Reifschneider, D., ve Williams, J. C. (2012). Have We Underestimated the Likelihood and Severity of Zero Lower Bound Events?, Journal of Money, Credit and Banking, 44(s1), 47-82.

Dahlhaus, T., Hess, K., ve Reza, A. (2014). International Transmission Channels of US Quantitative Easing: Evidence from Canada, Bank of Canada Working Paper, No. 14-43.

D’amico, S., English, W., Lopez-Salido, D., ve Nelson, E. (2012). The Federal Reserve's Largescale Asset Purchase Programmes: Rationale and Effects, The Economic Journal, 122(564), F415-F446.

D’amico, S., King, T. B. (2013). Flow and Stock Effects of Large-Scale Treasury Purchases: Evidence on the Importance of Local Supply, Journal of Financial Economics, 108(2), 425448.

Doh, T. (2010). The Efficacy of Large-Scale Asset Purchases at the Zero Lower Bound,
Federal Reserve Bank of Kansas City Economic Review, 95(2), 5-34.

Dye, R. F. (2004). State revenue cyclicality, National Tax Journal, 133-145.

Fratzscher, M., Duca, M. L., ve Straub, R. (2013). On the International Spillovers of US Quantitative Easing, ECB Working Paper, No. 1557.

Gagnon, J., Raskin, M., Remache, J., ve Sack, B. (2011). The Financial Market Effects of the Federal Reserve's Large-Scale Asset Purchases, International Journal of Central Banking, 7(1), $3-43$.

Gertler, M., ve Karadi, P. (2013). QE 1 vs. 2 vs. 3...: A Framework for Analyzing Large-Scale Asset Purchases as a Monetary Policy Tool, International Journal of Central Banking, 9(1), 5-53.

Georgiadis, G., ve Grab, J. (2016). Global Financial Market Impact of the Announcement of the ECB's Extended Asset Purchase Programme, Journal of Financial Stability, 26, 257-265.

Glick, R., ve Leduc, S. (2012). Central Bank Announcements of Asset Purchases and the Impact on Global Financial and Commodity Markets, Journal of International Money and Finance, 31(8), 2078-2101.

Glick, R., ve Leduc, S. (2013). The Effects of Unconventional and Conventional US Monetary Policy on the Dollar, Federal Reserve Bank of San Francisco Working Paper, No. 2013-11.

Hancock, D., ve Passmore, W. (2011). Did the Federal Reserve's MBS Purchase Program Lower Mortgage Rates?, Journal of Monetary Economics, 58(5), 498-514.

Joyce, M., Lasaosa, A., Stevens, I., ve Tong, M. (2011). The Financial Market Impact of Quantitative Easing in the United Kingdom, International Journal of Central Banking, 7(3), 113-161.

Kapetanios, G., Mumtaz, H., Stevens, I., ve Theodoridis, K. (2012). Assessing the 


\section{TÜRKAY}

Economy-Wide Effects of Quantitative Easing, The Economic Journal, 122(564), F316-F347.

Krishnamurthy, A., ve Vissing-Jorgensen, A. (2011). The Effects of Quantitative Easing on Interest Rates: Channels and Implications for Policy, NBER Working Paper, No. 17555.

Kozicki, S., Santor, E., ve Suchanek, L. (2011). Unconventional Monetary Policy: The International Experience with Central Bank Asset Purchases, Bank of Canada Review, 2011(Spring), 13-25.

Lenza, M., Pill, H., ve Reichlin, L. (2010). Monetary Policy in Exceptional Times, Economic Policy, 25(62), 295-339.

Li, C., ve Wei, M. (2013). Term Structure Modeling with Supply Factors and the Federal Reserve's Large-Scale Asset Purchase Progarms, International Journal of Central Banking, 9(1), 3-39.

Lim, J. J., ve Mohapatra, S. (2016). Quantitative Easing and the Post-Crisis Surge in Financial Flows to Developing Countries, Journal of International Money and Finance, Volume 68, 331-357.

Meaning, J., ve Zhu, F. (2011). The Impact of Recent Central Bank Asset Purchase Programmes, BIS Quarterly Review, December 2011.

Meinusch, A., ve Tillmann, P. (2016). The Macroeconomic Impact of Unconventional Monetary Policy Shocks, Journal of Macroeconomics, Volume 47, Part A, 58-67.

Moore, J., Nam, S., Suh, M., ve Tepper, A. (2013). Estimating the Impacts of US LSAP's on Emerging Market Economies' Local Currency Bond Markets, Federal Reserve Bank of New York Staff Report, No. 595.

Neely, C. J. (2015). Unconventional Monetary Policy Had Large International Effects, Journal of Banking \& Finance, 52, 101-111.

Pesaran, M. H., ve Smith, R. P. (2016). Counterfactual Analysis in Macroeconometrics: An Empirical Investigation into the Effects of
Quantitative Easing, Research in Economics, 70(2), 262-280.

Oda, N., ve Ueda, K. (2007). The Effects Of The Bank Of Japan'S Zero Interest Rate Commitment And Quantitative Monetary Easing On The Yield Curve: A Macro-Finance Approach, The Japanese Economic Review, 58(3), 303-328.

Swanson, E. T. (2011). Let's Twist Again: A High-Frequency Event-Study Analysis of Operation Twist and Its Implications for QE2, Brookings Papers on Economic Activity, 2011(1), 151-188.

Swanson, E. T., ve Williams, J. C. (2014). Measuring the Effect of the Zero Lower Bound on Medium-and Longer-Term Interest Rates, The American Economic Review, 104(10), 3154-3185.

Szczerbowicz, U. (2015). The ECB Unconventional Monetary Policies: Have They Lowered Market Borrowing Costs for Banks and Governments?. International Journal of Central Banking, 11(4), 91-127.

Thornton, D. L. (2012). Evidence on the Portfolio Balance Channel of Quantitative Easing, Federal Reserve Bank of St. Louis Working Paper Series, No. 2012-015.

Tillmann, P. (2016). Unconventional Monetary Policy and the Spillovers to Emerging Markets, Journal of International Money and Finance, 66, 136-156.

Weale, M., ve Wieladek, T. (2016). What Are the Macroeconomic Effects of Asset Purchases?, Journal of Monetary Economics, 79, 81-93. 